\title{
Growth and Maturation of Sargassum macrocarpum C. Agardh in Fukawa Bay, the Sea of Japan
}

\author{
Noboru Murase and Hitoshi Kito \\ National Fisheries University, Nagatahonmachi, Shimonoseki, Yamaguchi 759-6595, Japan \\ (Received September 22, 1997)
}

\begin{abstract}
Growth and maturation of Sargassum macrocarpum C. Agardh were studied in Fukawa Bay facing to the Sea of Japan, Yamaguchi Prefecture, at the depth of $8 \mathrm{~m}$, from June 1993 to July 1994. New main branches on perennial stem had been apparently observed in June, and grew increasingly through July to March in the next year, then reached the maximum length and dry weight of the branches in March and May, respectively. Thalli with three or more growth rings in holdfast matured and formed receptacles through March to June. The release of oospores and embryos was observed only in June. The number of main branches was almost the same among adult thalli and did not show variation throughout the year. The minimum and maximum standing crops were $257.6 \mathrm{~g} \mathrm{~m}^{-2}$ in August 1993 and $1155.7 \mathrm{~g} \mathrm{~m}^{-2}$ in May 1994, respectively.
\end{abstract}

Key words: Sargassum macrocarpum, growth, maturation, the Sea of Japan

Sargassum beds have been reported to play important ecological roles in the coastal ecosystem, due to high productivity. ${ }^{1-3)}$ Sargassum macrocarpum C. Agardh, a dominant perennial species of the Sargassum beds, is widely distributed from Chiba Prefecture to Kyushu Island facing the Pacific Ocean, and from Aomori Prefecture to Kyushu Island facing the Sea of Japan. This epilithic species usually grows at the depth of 10 meters or more.4)

In several perennial Sargassum species, it is pointed out that the periodical growth patterns of main branches play important roles in the population stability of Sargassum bed. ${ }^{3,-7)}$ In $S$. macrocarpum, however, no studies have been carried out from such viewpoints. This study investigated seasonal changes in main branch growth and standing crop of an S. macrocarpum population. Additionally, thalli maturation is also described in terms of the relationship between receptacle formation and the number of growth rings in holdfast.

\section{Materials and Methods}

The $S$. macrocarpum population was examined from June 1993 to July 1994 on a flat rock located at the depth of $8 \mathrm{~m}$ off Kiwado, Fukawa Bay facing the Sea of Japan, Yamaguchi Prefecture as shown in Fig. 1. Two quadrats of $50 \mathrm{~cm} \times 50 \mathrm{~cm}$ were randomly set within the $S$. macrocarpum population, and all individuals, including holdfasts, in the quadrat were collected. Samples were transported to the National Fisheries University and were measured by the following procedure.

The thalli exhibit deciduous main branches developing from the perennial stem. Main branches of adult thalli deteriorate over the winter and spring, approximately one year after development. ${ }^{1)}$ From early spring to late summer, there are two types of main branches, old ones and new ones, respectively. The former, which have sprouted during the previous year, are long and mature. The latter, which sprout during the present year, are short and imma-

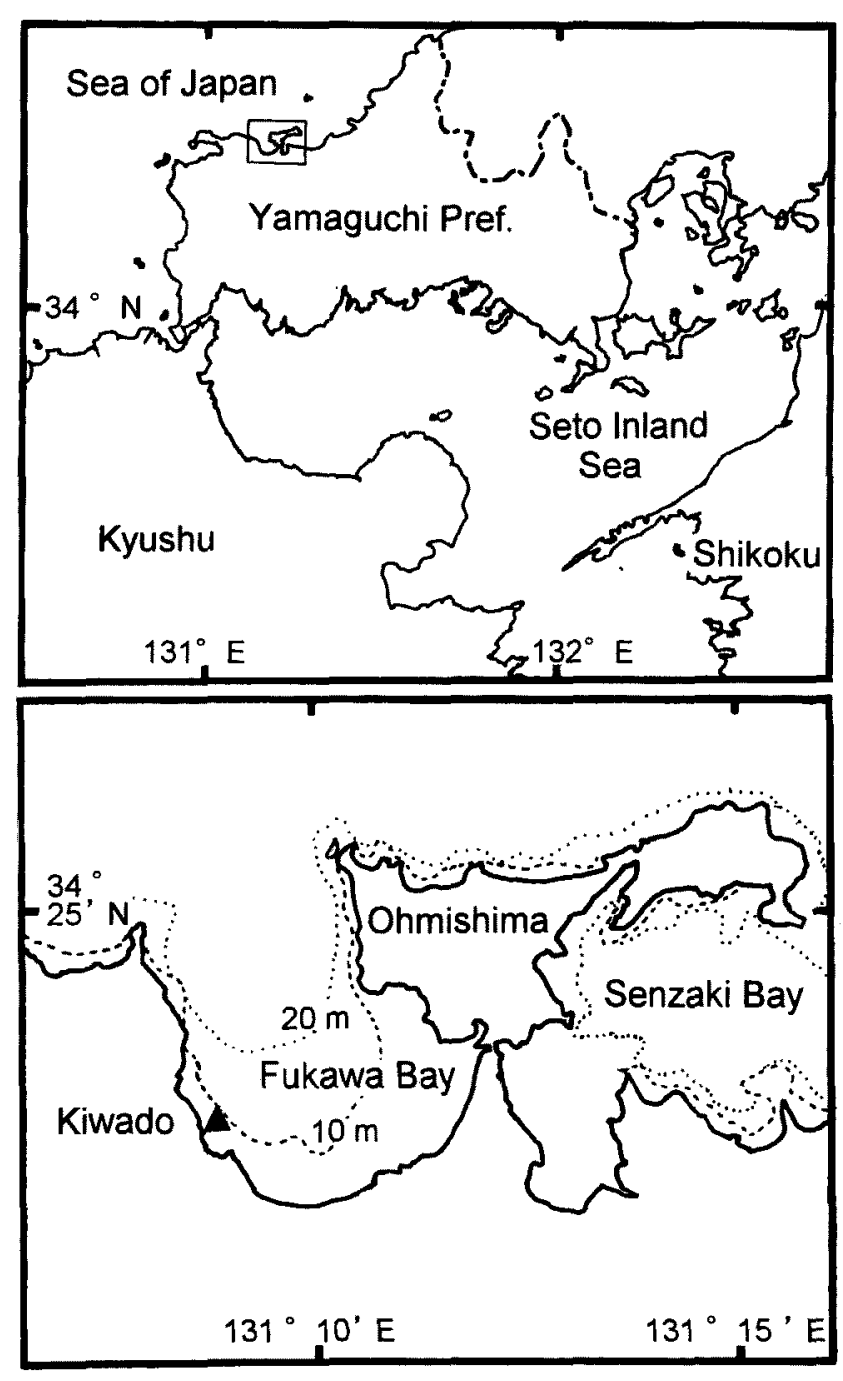

Fig. 1. Location of sampling station ( $\Delta$ ) in Fukawa Bay facing the Sea of Japan, Yamaguchi Prefecture. 
ture. The number of main branches and the length of thalli were measured in each quadrat. The length of thalli was measured from the holdfast to the apex of the longest main branch. A cross section of the holdfast was made to ascertain the number of concentric growth rings. Each sample without holdfast was rinsed in freshwater and dried at $80^{\circ} \mathrm{C}$ for 12 hours to obtain dry weights.

\section{Results}

Surface seawater temperature in Fukawa Bay is shown in Fig. 2. Data were averaged for every month for the five years from August 1989 to July 1994. The monthly mean seawater temperature ranged from $11.4^{\circ} \mathrm{C}$ in February to $25.7^{\circ} \mathrm{C}$ in August.

Mean length and dry weight of main branches per adult thallus are shown in Fig. 3(a) and 3(b), respectively. The number of growth rings in holdfast was counted from 0 to 9. Adult thalli, which had three or more growth rings, were long and mature in June 1993 at the start of this study. Young thalli, which had none to two growth rings, were short and immature at that time. The length and dry weight of adult thalli were $158.0 \mathrm{~cm}$ and $25.0 \mathrm{~g}$ for old branches, and $17.5 \mathrm{~cm}$ and $5.3 \mathrm{~g}$ for new branches, respectively, in June 1993. After releasing oospores and embryos, all of the old branches withered until September, by which time many new branches had already sprouted on the stem. The length and dry weight of new branches increased gradually from September to December and increased rapidly after December. In March 1994, thalli grew to the maximum length of $196.5 \mathrm{~cm}$, and bore receptacles. From March to May, the length of branches was almost constant from $170 \mathrm{~cm}$ to $190 \mathrm{~cm}$, although dry weight increased gradually. The mean dry weight of branches reached the maximum of $44.8 \mathrm{~g}$ in May. Main branches, which developed in 1993, withered after the release of oospores and embryos in June, 1994. Figure 3(c) showes monthly changes in the mean number of main branches per adult thallus. The number of main branches decreased temporarily to 7.9 individually in September 1993, due to the loss of the old main branches. Thereafter, new branches began to elongate on the stem. So, the total number of main branches did not change significantly throughout a year.

Individual density and standing crop including adult and young thalli are shown in Fig. 4. The density was high in June 1993 at the start of this study, then decreased from July 1993 through January 1994. From January to June

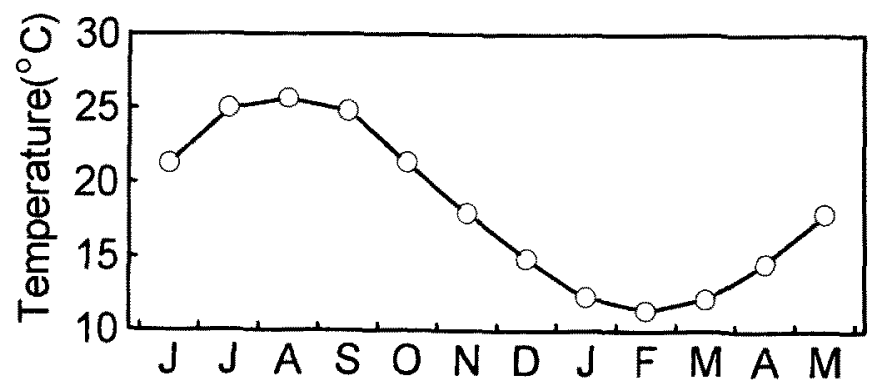

Fig. 2. Monthly changes of surface seawater temperature in Fukawa Bay.

Each data were averaged for the 5 years from August 1989 to July 1994.
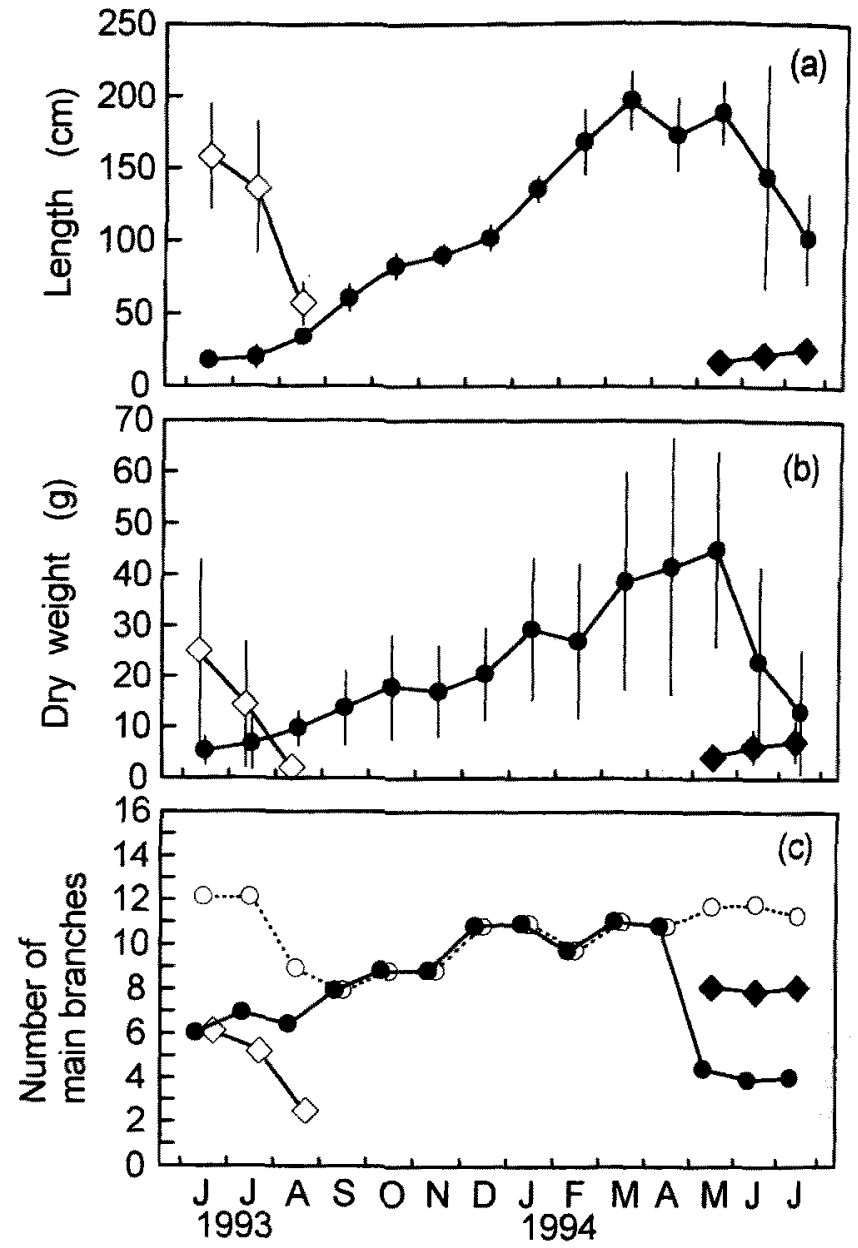

Fig. 3. Monthly changes of length (a), dry weight (b) and number (c) of main branches per adult Sargassum macrocarpum.

Closed circles represent new branches produced in 1993. Open diamonds illustrate main branches sprouted in 1992 and closed ones illustrate main branches sprouted in 1994. Open circles represent total number of main branches. Vertical bars indicate S.D.

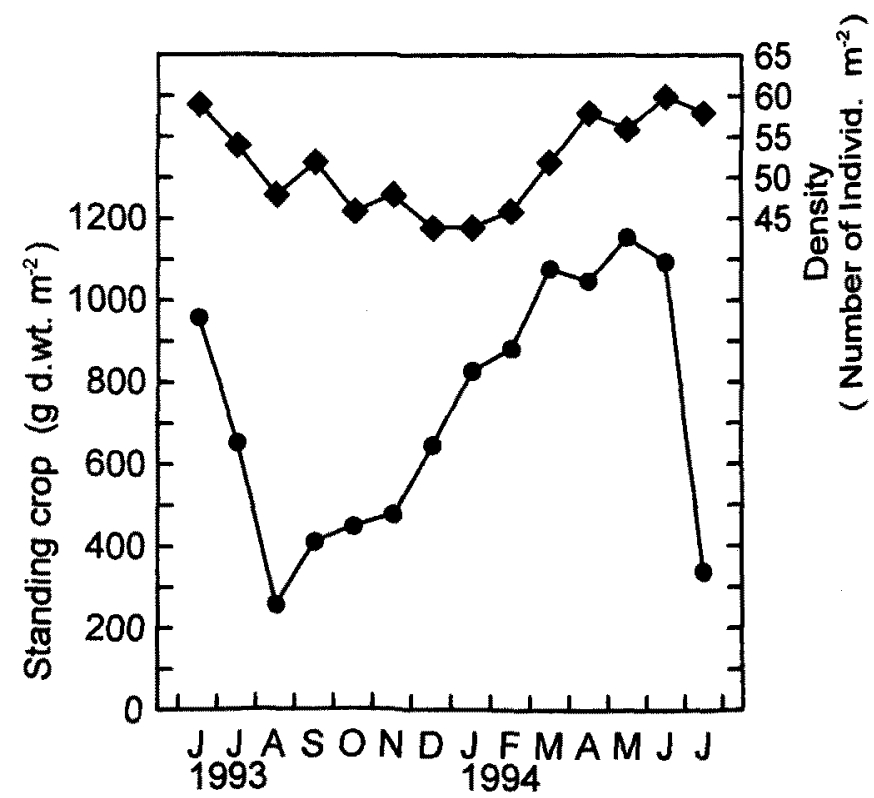

Fig. 4. Monthly changes of standing crop (--) and individual density (-) of the Sargassum macrocarpum population. 
Table 1. Monthly changes of the percentage of mature individuals bearing receptacles from June 1993 to July 1994, Each data were calculated among thalli with various number of growth ring

\begin{tabular}{|c|c|c|c|c|c|c|c|c|}
\hline & & \multicolumn{7}{|c|}{ Number of growth ring } \\
\hline & & 1 & 2 & 3 & 4 & 5 & 6 & 7 or more \\
\hline June & 1993 & $0.0(7)^{*}$ & $16.7(6)$ & $90.9(11)$ & $100.0(2)$ & $100.0(1)$ & - & - \\
\hline July & & $0.0(2)$ & $0.0(3)$ & $25.0(8)$ & $42.9(7)$ & $100.0(3)$ & - & $100.0(1)$ \\
\hline Aug. & & - & $0.0(5)$ & $0.0(6)$ & $0.0(5)$ & - & $0.0(1)$ & $0.0(1)$ \\
\hline Sept. & & $0.0(2)$ & $0.0(8)$ & $0.0(11)$ & $0.0(4)$ & $0.0(3)$ & $0.0(1)$ & - \\
\hline Oct. & & $0.0(4)$ & $0.0(5)$ & $0.0(5)$ & $0.0(4)$ & $0.0(2)$ & $0.0(3)$ & - \\
\hline Dec. & & - & - & $0.0(6)$ & $0.0(4)$ & $0.0(7)$ & $0.0(3)$ & - \\
\hline Jan. & 1994 & $0.0(2)$ & $0.0(2)$ & $0.0(1)$ & $0.0(6)$ & $0.0(3)$ & $0.0(4)$ & $0.0(3)$ \\
\hline Feb. & & $0.0(6)$ & - & $0.0(5)$ & $0.0(4)$ & $0.0(2)$ & $0.0(3)$ & $0.0(1)$ \\
\hline Mar. & & $0.0(1)$ & - & $0.0(6)$ & $20.0(5)$ & $33.3(3)$ & $50.0(6)$ & $50.0(2)$ \\
\hline Apr. & & $0.0(3)$ & $0.0(4)$ & $40.0(5)$ & $100.0(2)$ & $80.0(10)$ & $50.0(2)$ & $100.0(3)$ \\
\hline May & & $0.0(5)$ & - & $33.3(3)$ & $80.0(5)$ & $100.0(5)$ & $100.0(5)$ & $100.0(2)$ \\
\hline June & & $0.0(4)$ & $0.0(2)$ & $50.0(4)$ & $0.0(1)$ & $50.0(4)$ & $60.0(10)$ & $100.0(3)$ \\
\hline
\end{tabular}

* Number of collected plants in two quadrats.

1994, it increased, due to the existence of juvenile thalli as measured visually utilizing SCUBA. Densities of only adult thalli with three or more growth rings varied from 26 to 48 individuals per square meter, and it did not exhibit marked seasonal changes. The minimum and maximum standing crop were $257.6 \mathrm{~g} \mathrm{~m}^{-2}$ in August 1993 and $1155.7 \mathrm{~g} \mathrm{~m}^{-2}$ in May 1994 , respectively.

Monthly changes of the percentage of individuals bearing receptacles from June 1993 to July 1994 are shown in Table 1. In June 1993, 90.9-100\% of the adult thalli with three or more growth rings had receptacles. Oospores and embryos were released and attached to the surface of female receptacles. This process was observed again in June 1994. In July 1993, most of the thalli had already released oospores and embryos, and maintained empty receptacles. From August 1993 to February 1994, the receptacles were not observed in every group with various numbers of growth rings. In March 1994, the thalli with four or more growth rings began to bear receptacles. Thereafter, receptacles were formed in almost all of the thalli with three or more growth rings during April to June.

\section{Discussion}

The present study elucidated the seasonal changes in growth and maturation of $S$. macrocarpum populations in Fukawa Bay at a depth of $8 \mathrm{~m}$. Receptacles on main branches were born from March through July. The maturation accelerated in June, by means of the visible observation of release of oospores and embryos on female receptacles. Additionally, the receptacles were born in the majority of thalli with three or more growth rings. The maturity of $S$. ringgoldianum subsp. coreanum on the northern and western coasts of Kyushu was about $50 \%$ of the individuals with two growth rings and $100 \%$ of those with three or more growth rings. ${ }^{8)}$ The tendency of the maturity of $S$. ringgoldianum subsp. coreanum almost coincided with the result found in the present study for $S$. macrocarpum. Yoshida ${ }^{8)}$ also reported that the growth ring in holdfast formed periodically once a year, and could be called an annual ring. As a growth ring of $S$. macrocarpum is con- sidered to be an annual ring the same as $S$. ringgoldianum subsp. coreanum, $S$. macrocarpum begins to mature in the second year and the longevity of this species is eight or nine years.

Adult thalli of $S$. macrocarpum with three or more growth rings were used in this study to clarify seasonal changes in individual growth. Adult ones played the main role in the seasonal changes of standing crop of the $S$. macrocarpum population. During the period from June to August, old branches withered and new branches had already developed on the stem of the adult thallus. Minimum standing crop and maximum temperatures were recorded in August. Dry weight of an adult thallus and standing crops increased gradually from August and reached the maximum in May. Formation of receptacles began in March, and oospores and embryos were released in June. Thereafter, all matured main branches withered until September. Such similar growth patterns of main branches were reported in other perennial Sargassum species in temperate waters. ${ }^{3,5-7)}$ For example, the main branches of $S$. miyabei in Maizuru Bay elongate from November to June, and dry weight of the branches increases from June to July. ${ }^{6}$ The mature season of this species was from June to July. Many main branches of S. siliquastrum on the northern and western coasts of Kyushu sprout on the stem from fall to winter. ${ }^{7)}$ The branches of this species form vesicles and elongate in winter. Thereafter, the thalli mature in spring and all of the branches wither until summer. Also, several species of Sargassum in subtropical and tropical waters have periodically deciduous main branches on the perennial stem and/or holdfast. ${ }^{9-11}$ Therefore, it is thought that the population of perennial Sargassum species is maintained by the seasonal dynamic changes of standing crop and population height with correlation to the mature season.

Taniguchi and Yamada ${ }^{\text {l) }}$ reported that seasonal changes of $S$. macrocarpum population in lida Bay were segregated into four periods: 1) sprouting period, new main branches become visible on perennial stem, 2) elongating period, main branches elongate rapidly as the seawater temperatures falls, 3) thickening period, individual weight in- 
creases as the seawater temperatures rises, and 4) mature period, production of oospores and embryos in female receptacles. In the present study, almost the same seasonal changes were observed in the $S$. macrocarpum population in Fukawa Bay.

The maximum standing crop of $S$. macrocarpum measured in this study was $1155.7 \mathrm{~g} \mathrm{~m}^{-2}$ in May, and that in Iida Bay was $7074.6 \mathrm{~g} \mathrm{~m}^{-2}$ in April. ${ }^{1)}$ In the period of the maximum standing crop, the individual density in Fukawa Bay was approximately three times higher than that in Iida Bay. However, the population height in Fukawa Bay was approximately half of that in Iida Bay. Additionally, the number of main branches of adult thalli in Fukawa Bay was only $20 \%$ of that in Iida Bay. The difference of the standing crop between in Fukawa Bay and in Iida Bay may be caused by the difference in growing depths, $8 \mathrm{~m}$ in the former study and 4-6 $\mathrm{m}$ in the latter, and by the difference in the size of adult thalli.

In the present study, seasonal changes of standing crop, thalli height, individual density, and growth and mature season of $S$. macrocarpum were clarified. It was shown that, periodical growth patterns of main branches play important roles in the population stability of $S$. macrocarpum. In addition, it was thought that successful annual recruitment of juvenile thalli is also essential to population stability. ${ }^{12)}$ In future, it will be necessary to clarify the population dynamics in detail and determine the annual net production of $S$. macrocarpum.

Acknowledgments We sincerely wish to thank Dr. T. Yoshida of the Faculty of Science, Hokkaido University for his useful advice on the identification of our materials. We are very grateful to Mr. N. Kakuda of Yamaguchi Prefectural Gaikai Fisheries Experimental Station for seawater temperature data, and to the Fishermen's Union in Kiwado, Yamaguchi Prefecture for permission to use their administrative waters. We wish to express thanks also to Dr. M. Maegawa of the Faculty of Bioresources, Mie University for reading the manuscript. This work was supported by a grant from the Biocosmos Plan of the Ministry of Agriculture, Forestry, and Fisheries Agency, Japan, under contribution No. BCP 97-IV-D-1.

\section{References}

1) K. Taniguchi and Y. Yamada: Ecological study on Sargassum patens $\mathrm{C}$. Agadh and S. serratifolium C. Agardh in the sublittoral zone at Iida Bay of Noto Peninsula in the Japan Sea. Bull. Jap. Sea Reg. Fish. Res. Lab. 29, 239-253 (1978).

2) K. Taniguchi and H. Yamada: Annual variation and productivity of the Sargassum horneri population in Matsushima Bay on the Pacific Coast of Japan. Bull. Tohoku Reg. Fish. Res. Lab. 50, 5965 (1988).

3) I. Umezaki: Growth of the primary laterals in Sargassum ringgoldianum Harv. subsp. coreanum (J. Ag.) Yoshida in Obama Bay Japan Sea. Bull. Japan. Soc. Sci. Fish., 52, 957-963 (1986).

4) T. Yoshida: Japanese species of Sargassum subgenus Bactrophycus (Phaeophyta, Fucales). J. Fac. Sci. Hokkaido Univ. Ser. V(Bota. $n y), 13,99-246$ (1983).

5) I. Umezaki: Ecological studies of Sargassum thunbergii (Mertens) O. Kuntze in Maizuru Bay, Japan Sea. Bot. Mag. Tokyo, 87, 285292 (1974).

6) I. Umezaki: Ecological studies of Sargassum miyabei Yendo in Maizuru Bay, Japan Sea. Bull. Japan. Soc. Sci. Fish., 49, 18251834 (1983).

7) N. Nanba and T. Okuda: Growth of main branches of Sargassum siliquastrum at Tuyazaki, Japan. Nippon Suisan Gakkaishi, 59, 1675-1678 (1993).

8) T. Yoshida: On the growth rings found in the root of Sargassum ringgoldianum Harvey (Fucales), Bull. Japan. Soc. Sci. Fish. 26, 673-678 (1960).

9) J. S. Prince and S. W. O'neal: The ecology of Sargassum pteropleuron Grunow (Phaeophyceae, Fucales) in the waters off South Florida. I. Growth, reproduction and population structure. Phycologia, 18, 109-114 (1979).

10) P. O. Ang. Jr.: Preliminary study on the alginate contents of Sargassum spp. in Balibago, Calatagan, Philippines. Hydrobiologia, 116/ 117, 547-550 (1984).

11) P. O. Ang. Jr.: Regeneration studies of Sargassum siliquosum J. Ag. and S. paniculatum J. Ag. (Phaeophyta, Sargassaceae). Bot. Mar., 28, 231-235 (1985).

12) M. Maegawa: Ecological studeies of Eisenia bicyclis (Kjellman) Setchell and Ecklonia cava Kjellman. Bull. Fac. Bioresources Mie Univ., 4, 73-145 (1990). 